\title{
Radiological Hazard Indices in Federal University of Lafia (FULafia), Nasarawa State.
}

\author{
Bello Aisha $\mathrm{A}^{1^{*}}$ Zahra Liman $^{1}$ Olorunsola Abel Keneth Ogbo ${ }^{1}$ Abdullahi Hassan A. ${ }^{2}$ \\ 1. Department of Physics, Federal University of Lafia, Nasarawa State, Nigeria \\ 2. National Agency for Science and Engineering Infrastructure, Garki, Abuja \\ *E-mail of the corresponding author: belloaisha320@yahoo.com
}

\begin{abstract}
An assessment of radiological hazard indices from background radiation exposure was carried out in FULafia using a Mobile GPS for locational coordinates and a Ludlum radiation meter. Holding the survey meter $1 \mathrm{~m}$ above the ground level in the exposure mode, a total of 71 sample points comprising of indoor and outdoor locations in Takeoff site (TS) and permanent site (PS) of the University was used for exposure measurement. Result showed that the indoor and outdoor mean absorbed dose is (136.51 \pm 7.46$) n G y h^{-1}$ and (131.26 \pm 2.09$) n G y h^{-1}$ respectively. The total indoor and outdoor average values for annual effective absorbed dose equivalent (AEDE), Excess lifetime cancer risk (ELCR) and AEDE to organ was found to be $(0.81 \pm 0.02) \mathrm{mSvy}^{-1},(2.84 \pm 0.07) \times 10^{-3}$, and $(0.35 \pm 0.01) \mathrm{mSvy}^{-1}$. These values when compared with UNSCEAR limit of radiological indices for the general public where higher but lower when compared with ICRP limit of $1 \mathrm{mSvy}^{-1}$ thus; there is no health concern due to the exposure from background ionizing radiation in FULafia, Nasarawa state.
\end{abstract}

Key words: Ionizing radiation, Occupancy factor, Cancer risk factor, Conversion coefficient.

DOI: $10.7176 /$ APTA/83-10

Publication date: November $30^{\text {th }} 2020$

\section{Introduction}

In order to promote a sustainable and environmentally accepted condition, background radiation in an environment should be properly monitored. Conscious of the environmental implication of these radiation, International Commission on Radiological Protection (ICRP), United Nations Scientific Committee on the effect of Atomic Radiation (UNSCEAR) and other related bodies have provided limits to keep these radiations to as low as reasonably possible. Background radiation in this work refers to ionizing radiations that occur naturally in the environment but can also occur due to human activity.

Terrestrial and cosmic sources are all contributors of natural source of background radiation. The radiation due to cosmic rays is about $0.26 \mathrm{mSv} / \mathrm{yr}$ at sea level and is due mainly to ${ }^{3} \mathrm{H}$ and ${ }^{14} \mathrm{C}$ radionuclides. This varies from place to place depending on the geomagnetic latitude and mainly due to altitude above sea level. Terrestrial background radiation occur mainly due to uranium minerals present in both rocks and soil and varies from place to place with concentration that ranges from 1 to $4 \mathrm{ppm}$ in sedimentary and granite rocks to $150 \mathrm{ppm}$ in phosphate deposits (Eisenburd \& Paschoa, 1989).

The major source of concern to background radiation from Uranium is its daughter radionuclide ${ }^{226} \mathrm{Ra}$ which decays to ${ }^{222} \mathrm{Rn}$ a noble gas known for its inertness and can easily diffuse and attach itself to dust particles in the atmosphere which when inhaled can deposit in the lung. Exposure to Radon may be elevated within buildings because the gas diffuses into them from soil, wall materials or underground water. On average Radon indoor radiation exposure is about $1.4 \mathrm{mSv}$ but varies from place to place depending on the degree of Uranium content in the soil and rock. Estimate shows that about 15000 to 20000 deaths from lung cancer may be caused annually by radon exposure in the US homes which could be higher among cigarette smokers (Sadiq \& Agba, 2011).

Internal and external radionuclide sources that contributes to natural background radiation exposures includes ${ }^{210} \mathrm{~Pb},{ }^{210} \mathrm{Po}$, and ${ }^{40} \mathrm{~K}$ among others. The rate of exposure to these sources may vary over time due to social changes such as living in houses, smoking cigarettes, using phosphate fertilizers, flying air planes, construction and excavation of soils. Other contributors to environmental radiation are from medical and dental practices, consumer products, nuclear fuel cycle, mining and milling, nuclear reactors, reprocessing spent fuel, transportation of radioactive materials, radioactive wastes and nuclear sources just to mention a few.

This work covers the stochastic radiological hazard assessment of background radiation in Federal University of 
Lafia, Nasarawa State. For stochastic effect, the probability of occurrence increases with the dose received as there is no dose threshold. Thus, any dose received above zero could lead to cancer and genetic damage many years after exposure. Lots of research has been carried out on assessment of environmental background radiation in Nigeria among which are (Ekong et al., 2019), (Ezekiel, 2017), (Sadiq \& Agba, 2011,) but the absence of a threshold leading to an incremental radiological risk above zero dose give room for concern about continuous assessment of background radiation and its radiological impact in any environment, FULafia inclusive.

Since the creation of the University in 2011, the University administration has continued to increase its staff strength and student as more courses are being accredited. These developments call for more supporting infrastructure for both staff and student. It is against this backdrop that the University is carrying out some massive constructions, like the excavation of land, construction of roads, erecting of new buildings and even the equipment used in building. The excavation helps in the transfer of radionuclides, which could contribute to background ionizing radiation within the University. Thus the need to survey the level of indoor and outdoor radiation levels with reference to the maximum allowable level within the University. Researchers have shown that a life time cancer risk per person of about $10^{-6}$ is negligible but when multiplied by a large number of persons in a population, it could yield radiation induced cancer that may warrant public health official attention (Eisenburd \& Paschoa, 1989).

The aim of this work is to carry out radiological hazard assessment of background radiation from some selected locatios and buildings within Federal University of Lafia, Nasarawa State, Nigeria.

\section{Materials and Methods}

The Federal University of Lafia is located in Lafia the capital of Nasarawa state, Nigeria. It has coordinates $8^{\circ} .50^{\prime} 60^{\prime \prime} \mathrm{N}$ and $8^{\circ} .52^{\prime} 27^{\prime \prime} \mathrm{E}$.

\subsection{Experimental Method}

A mobile GPS was used to obtain locational data, measurements were carried out using a calibrated Geiger Müller counter; Ludlum Model 19 Micro R Meter with serial no 207422. The meter was suspended in air at one meter above the ground level based on ICRP specifications. Readings were obtained between the hours of $9 \mathrm{am}$ to $5 \mathrm{pm}$ in the month of September, 2019. Five readings were taken at each indoor and outdoor location to include class rooms, offices, student hostels, construction sites and fields among others for temporary and permanent site of the University and the mean values were recorded in micro Roentgen per hour ( $\mu \mathrm{R} / \mathrm{hr}$ ). There was no special code name assigned to each location where data was gotten as the buildings retained the usual name assigned or the names of the occupants. Measurements were carried out in 71 sampled locations with 54 locations for indoor and outdoor locations in permanent site and 17 sampled locations in takeoff site.

\subsection{Dose Calculation}

The mean exposure rate in $\mu \mathrm{R} / \mathrm{hr}$ for each location was converted to absorbed dose in air, annual effective absorbed dose equivalent (AEDE), effective dose to different body organs (AEDE organ$)$, and Excess lifetime cancer risk (ELCR) using equations (1), (2), (3) and (4) as used by (Ezekiel, 2017) and (Rafique et al., 2014).

$$
\begin{gathered}
1 \mu R h^{-1}=8.77 n G y h^{-1} \\
A E D E\left(m S v y^{-1}\right)=\operatorname{DoseRate}\left(n G y^{-1}\right) \times 8760 h y^{-1} \times 0.2 \times 0.7 s v G y^{-1} \times 10^{-6} \\
A E D E_{\text {organ }}\left(m S v y^{-1}\right)=A E D E \times F \times O \\
E C L R=A E D E\left(m S v y^{-1}\right) \times D L \times R F
\end{gathered}
$$

Where

$0.7 S v G y^{-1}$ is the conversion coefficient from absorbed dose in Air, 0.2 is the external occupancy factor proposed by UNSCEAR (UNSCEAR, 2008), $8760 h$ is the number of hours in a year, and $F$ is the conversion factor of organ dose from air dose. The $F$ value for whole body, lungs, ovaries, bone marrow, testes, kidney, and liver as given by ICRP are $0.68,0.64,0.58,0.69,0.82,0.62$, and 0.46 respectively (ICRP, 1996). The occupancy factor $(O)$ is 0.8 for indoor occupancy and 0.2 for outdoor occupancy. The average duration of life (DL) is given as 70 years and $\mathrm{RF}$ is the fatal cancer risk factor per sievert $\left(\mathrm{Sv}^{-1}\right)$. For low dose background radiation, which is considered to produce stochastic effects, ICRP 103 uses a fatal cancer risk factor value of 0.05 for public exposure (ICRP, 1960) 


\section{Results and Discussion}

The study set out to assess the radiological hazard indices associated with background radiation in Federal University of Lafia. Figure 1 and Figure 2 shows the graph of radiological hazard indices for assessed outdoor and indoor locations for Permanent site (PS) and Take off site (TS) of the University respectively. Table 1 shows statistics on radiological hazard indices obtained from measured exposure in air at various locations within the University comprising of absorbed dose rate in air $\left(\mathrm{nGyh}^{-1}\right)$, annual effective dose equivalent (AEDE $\left.\mathrm{mSvy}^{-1}\right)$, mean dose to some selected organs of the body $\left(\mathrm{mSvy}^{-1}\right)$ and excess life cancer risk (ELCR) as it compares with world average. Figure 3 shows a plot of radiological hazard indices of our study in comparison with UNSCEAR limits, result from some academic institutions and other locations.

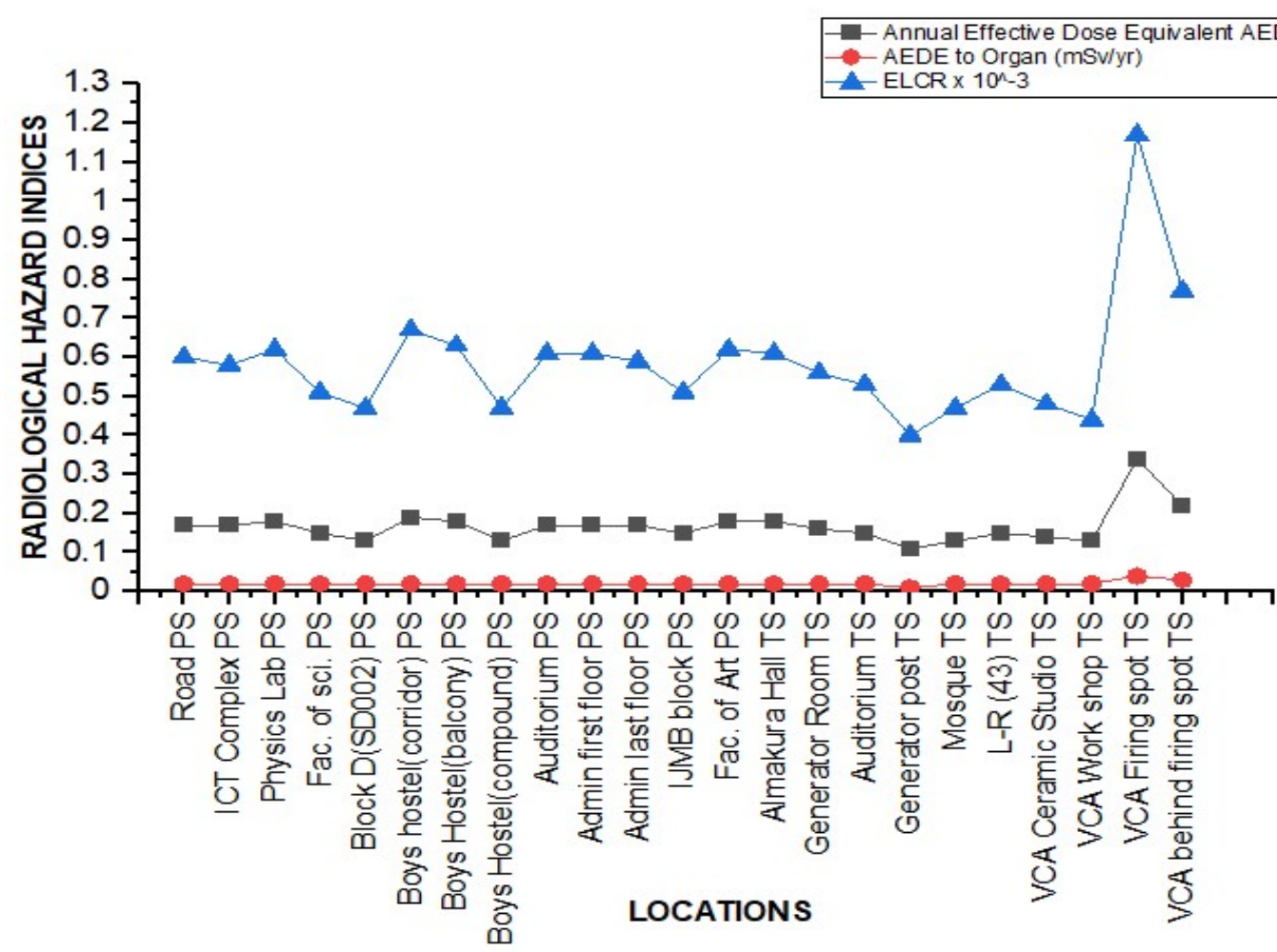

Figure 1: Plot of Outdoor Radiological Hazard Indices (AEDE, AEDE to Organ, ELCR) for various assessed locations in FULafia 


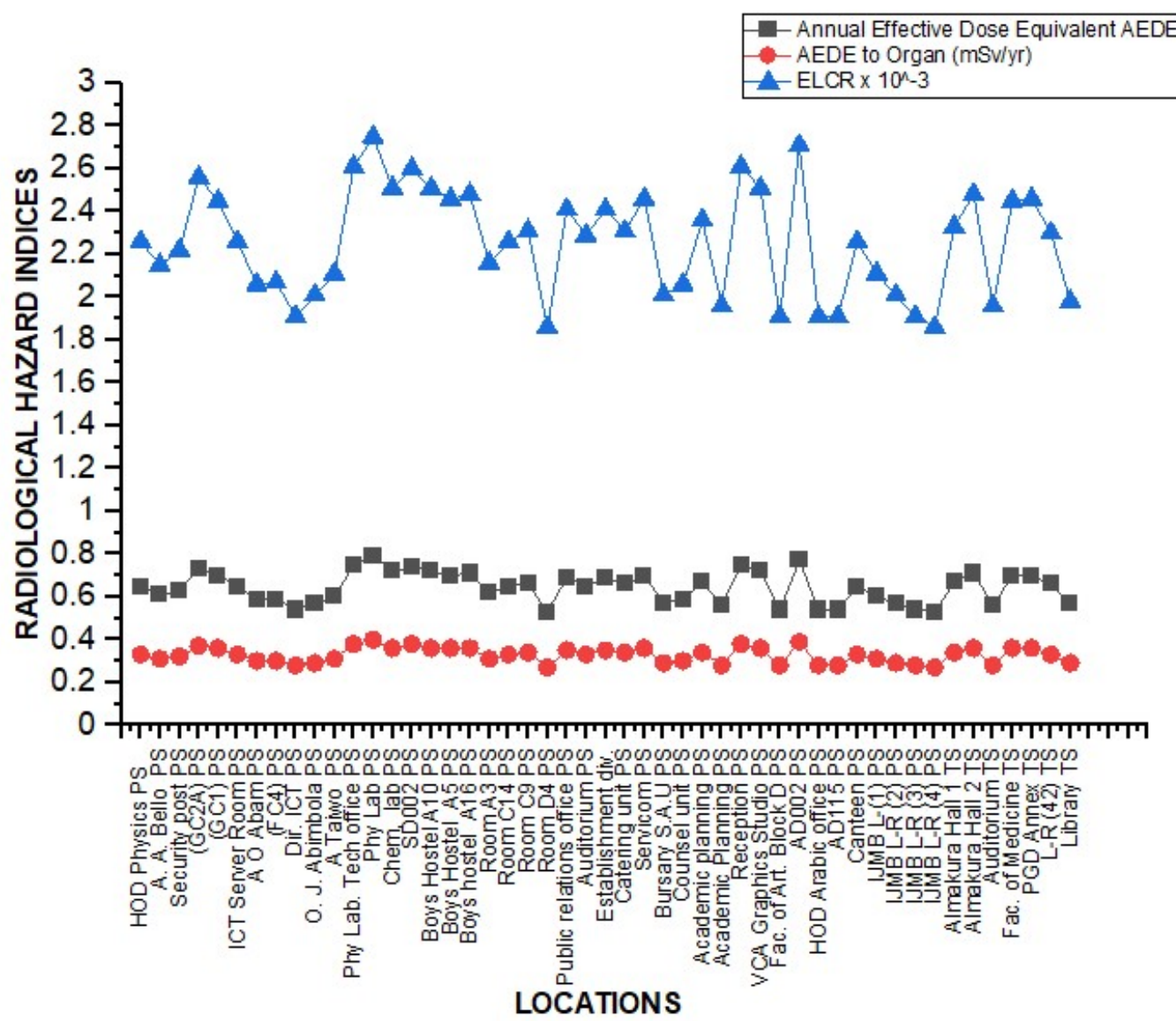

Figure 2: Plot of Indoor Radiological Hazard Indices (AEDE, AEDE to Organ, ELCR) for various assessed locations in FULafia 
Table 1: Statistics on Radiological Hazard Indices from Outdoor and Indoor Exposure in Permanent Site (PS) and Take-off Site (TS) of FULafia.

\begin{tabular}{|c|c|c|c|c|c|}
\hline Radiation Indices & Minimum & Maximum & $\begin{array}{l}\text { This Work } \\
\text { Average }\end{array}$ & $\begin{array}{l}\text { Standard } \\
\text { Dev. }\end{array}$ & World Average $^{a}$ \\
\hline Dout $\left(n G y h^{-1}\right)$ & 93.49 & 273.62 & $136.51 \pm 7.46$ & 35.79 & 59.00 \\
\hline $\operatorname{Din}\left(n G y h^{-1}\right)$ & 108.13 & 160.05 & $131.26 \pm 2.09$ & 14.61 & 84.00 \\
\hline $\operatorname{AEDE}_{\text {out }}\left(\mathrm{mSvy}^{-1}\right)$ & 0.11 & 0.34 & $0.17 \pm 0.01$ & 0.04 & 0.07 \\
\hline $\operatorname{AEDE}_{\text {in }}\left(\mathrm{mSvy}^{-1}\right)$ & 0.53 & 0.79 & $0.64 \pm 0.01$ & 0.07 & 0.41 \\
\hline $\operatorname{AEDE}\left(\mathrm{mSvy}^{-1}\right)$ & 0.64 & 1.13 & $0.81 \pm 0.02$ & 0.11 & 0.52 \\
\hline $\mathbf{E L C R}_{\text {out }} \times 10^{-3}$ & 0.40 & 1.17 & $0.59 \pm 0.03$ & 0.15 & 0.29 \\
\hline $\operatorname{ELCR}_{\text {in }} \times 10^{-3}$ & 1.86 & 2.75 & $2.25 \pm 0.04$ & 0.25 & 1.16 \\
\hline $\operatorname{ELCR} \times 10^{-3}$ & 2.26 & 3.92 & $2.84 \pm 0.07$ & 0.40 & 1.45 \\
\hline $\begin{array}{l}\text { AEDE }{ }_{\text {out }} \text { Organ }\left(\mathrm{mSvy}^{-}\right. \\
\text {1) }\end{array}$ & 0.01 & 0.04 & $0.02 \pm 0.001$ & 0.01 & \\
\hline $\operatorname{AEDE}_{\text {in }}$ Organ $\left(\mathrm{mSvy}^{-1}\right)$ & 0.27 & 0.40 & $0.33 \pm 0.01$ & 0.04 & \\
\hline AEDE Organ $\left(\mathrm{mSvy}^{-1}\right)$ & 0.28 & 0.44 & $0.35 \pm 0.01$ & 0.05 & \\
\hline
\end{tabular}

a Qureishi et al., (2014) 


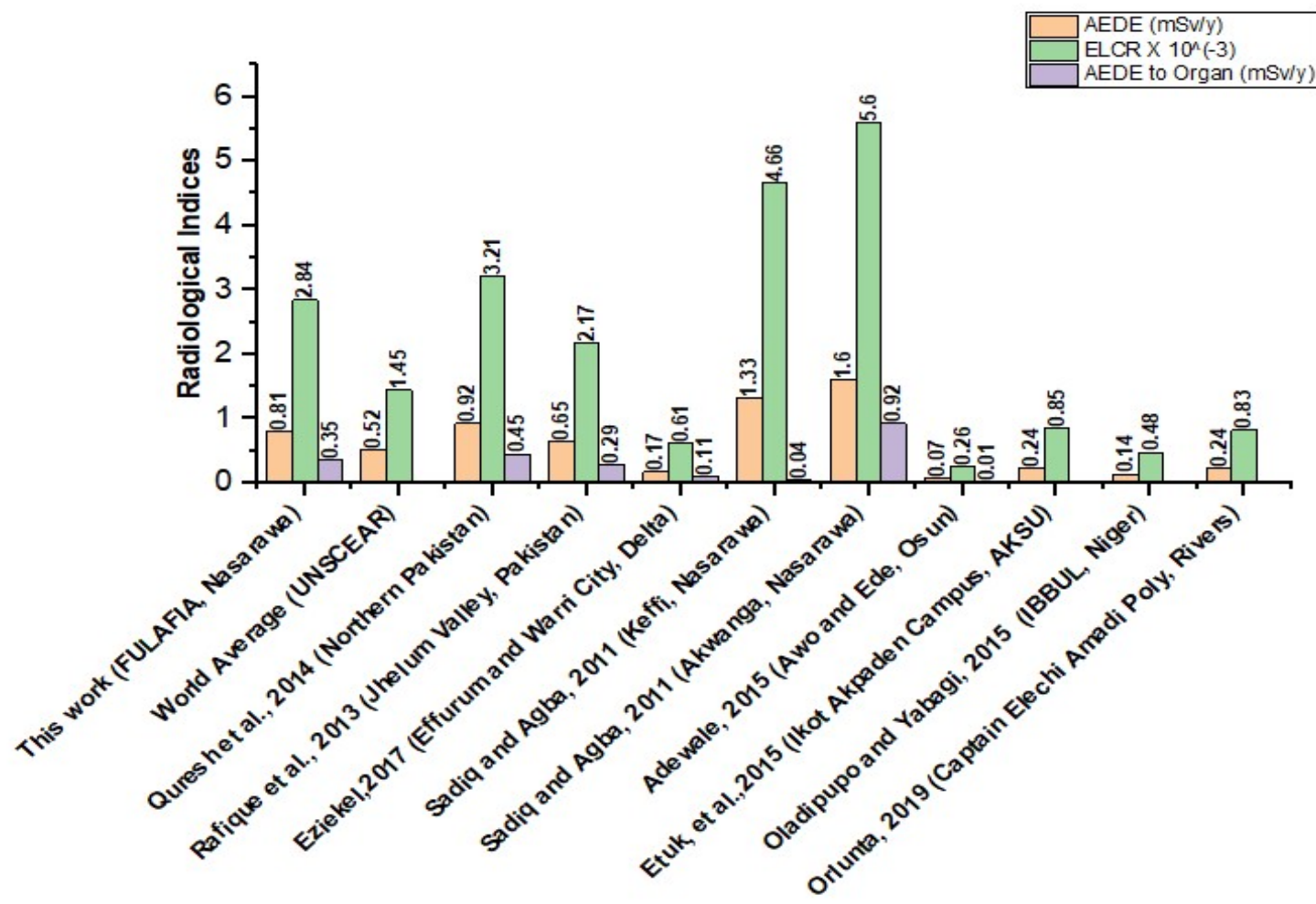

Figure 3: This work radiological indices as it compares with world average values, values from some academic institutions and other Authors

\subsection{Absorbed dose rate, $D\left(n G y h^{-1}\right)$}

The absorbed dose rate from outdoor gamma exposure in air was calculated using equation 1 . The minimum and maximum absorbed dose rate is $93.49 n G y h^{-1}$ and $273.62 n G y h^{-1}$ corresponding to the location of the generator house at permanent site and Faculty of Art visual and Creative Art (VCA) firing spot at the takeoff site respectively with a mean value of $136.51 n G y h^{-1}$. The minimum and maximum indoor absorbed dose rate is $108.13 n G y h^{-1}$ and $160.5 n G y h^{-1}$ with a mean value of $131.26 n G y h^{-1}$.

\subsection{Annual effective dose equivalent (AEDE) $\mathrm{mSvy}^{-1}$}

The AEDE was calculated from absorbed dose rate using equation 2. The average outdoor for AEDE for all site was $0.17 \mathrm{mSvy}^{-1}$ with values ranging from 0.11 to $0.34 \mathrm{mSvy}^{-1}$ while the average indoor AEDE was $0.64 \mathrm{mSvy}$ with minimum and maximum values of $0.53 \mathrm{mSvy}^{-1}$ and $0.79 \mathrm{mSvy}^{-1}$ corresponding to lecture Room D4 and Physics Lab all at PS

\subsection{Dose to Organ $\mathrm{mSvy}^{-1}$}

Using the dose to organ conversion factor as recommended by ICRP, equation 3 was used to calculate the mean dose that would be delivered to the whole body, lungs, ovaries, bone marrow, testes, kidney, and liver as a result of the outdoor exposure. This was found to be $0.02 \mathrm{mSvy}^{-1}$ with values ranging from $0.01 \mathrm{mSvy}^{-1}$ to $0.04 \mathrm{mSvy}^{-1}$ with the highest value corresponding to the VCA firing spot at takeoff site. An average value of $0.33 \mathrm{mSvy}^{-1}$ with values ranging from $0.27 \mathrm{mSvy}^{-1}$ to $0.40 \mathrm{mSvy}^{-1}$ was gotten for indoor dose to organ.

\subsection{Excess life cancer risk ELCR}

The life time fatality probability coefficient of $5 \times 10^{-2}$ for a reference population of all ages as proposed by UNSCEAR was used to estimate the ELCR which is the risk of contracting cancer as a result of exposure to a measured radiation for a given life time. This was calculated from the values of AEDE using equation (4). The mean outdoor ELCR for both TS and PS was found to be $0.59 \times 10^{-3}$ with values ranging from $0.40 \times 10^{-3}$ to 1.17 $\times 10^{-3}$ and an average value of $2.25 \times 10^{-3}$ for indoor ELCR with values ranging from $1.86 \times 10^{-3}$ to $2.75 \times 10^{-3}$.

As shown in Figure 3, comparing the average values of radiological indices in this work with world average, the 
absorbed dose rate, AEDE and ELCR is higher than that of UNSCEAR with total average values of $267.77 n G y h^{-}$ ${ }^{1}, 0.81 \mathrm{mSvy}^{-1}$, and $2.84 \times 10^{-3}$ against the world average value of $143 n G y h^{-1}, 0.52 \mathrm{mSvy}^{-1}$ and $1.45 \times 10^{-3}$. The values of total AEDE and ECLR in this work is higher when compare with those of Rafique et al., (2014), Ezekiel, (2017), Adewale, Tubosun \& Ojo (2015), also in Etuk et al., (2015), Oladipupo \& Yabaji, (2015) as cited in (Orlunta, Sokari, \& Anele, 2019). While we have lower values compared with that of Qureshi et al., (2014) and that calculated from Sadiq \& Agba (2011). Our total value for AEDE to organ of $1.35 \mathrm{mSvy}^{-1}$ is higher when compared to the work of other authors such as Qureshi et al., (2014) and that calculated from Sadiq \& Agba, (2011). While we have a lower value of AEDE to organ when compared with works of Rafique et al., (2013), Eziekel, (2017), calculated value from Sadiq \& Agba, (2011) Adewale et al., (2015).

We noticed the highest value of outdoor exposure at the VCA firing spot take off site as shown in Figure 2, this could be as a result of radiological content from the naturally occurring radionuclides mainly U-238, and the Th232 series in the clay soil used for pottery in the department of VCA of FULafia..

A statistic of Pearson Correlation on the indoor and outdoor values of AEDE from the take-off site and the permanent site shows a value of $r=0.32$ at a 0.05 confidence level and a correlation coefficient highly significantly different from zero $(\mathrm{P}=0.018)$ indicates that the strength of association between the source of exposure from which the annual effective dose equivalent was calculated varied between the locations. Other factors that could cause this small correlation could be as a result of non-uniform sample size, lack of adequate control of the sample location, and extraneous effects other than that due to radiation exposure such as varying weather condition during the period of data collection.

\section{Conclusion}

An assessment of radiological hazard indices from background radiation in Federal University of Lafia was carried out. The indoor and outdoor mean absorbed dose was found to be (136.51 \pm 7.46$) n G y h^{-1}$ and (131.26 \pm 2.09$) n G y h^{-}$ ${ }^{1}$. The total indoor and outdoor average values for AEDE, ELCR and AEDE to organ was found to be $(0.81 \pm 0.02)$ $m S v y^{-1},(2.84 \pm 0.07) \times 10^{-3}$, and $(0.35 \pm 0.01) m S v y^{-1}$. These values when compared to UNSCEAR limit of radiological indices for a populace the values where higher but lower when compared with ICRP limit of $1 \mathrm{mSvy}$

${ }^{l}$ thus, we conclude that there is no health concern due to the exposure from ionizing radiation in FULafia. Despite this result, continuous assessment of background ionizing radiation in FULafia should always be carried out on a frequent basis to ascertain compliance with regulatory standards.

Suggested future work include elemental analysis of radiation particles found in FULafia water path.

\section{References}

Adewale, O. O.; Tubosun, I. A.; Ojo, J. O. (2015) Assessment Terrestrial Naturally Occurring Radioactive Material in soil and mine tailings in Awo and Ede, Osun-State, South West Nigeria. Ife Journal of Science, 17 (1), 199-209.

Eisenbud, M., \& Paschoa, A. S. (1989). Environmental Radioactivity. Nuclear Instrument Methods in Physics Research A280, 470 - 482. North - Holland, Amsterdam.

Ekong, G., Akpa, T., Umaru, I., Lumbi, W., Akpanowo, M., \& Benson, N. (2019). Assessment of Radiological Hazard Indices from Exposures to Background Ionizing Radiation Measurements in South-South Nigeria. International Journal of Environmental Monitoring and Analysis, 7(2), 40. https://doi.org/10.11648/j.ijema.20190702.11

Eshiett, P, Joseph D. Z., Egga, A., Matthew, A., Abdullahi,, M. K. G. (2015). Assessment of Background Radiation Levels at the Radiology Department of a Tertiary Hospital in North-central Nigeria. Journal of The Association of Radiographers of Nigeria, 29 (1), 47-51.

Ezekiel, A. O. (2017). Assessment of excess lifetime cancer risk from gamma radiation levels in Effurun and Warri city of Delta state, Nigeria. Journal of Taibah University for Science, 11(3), 367-380. https://doi.org/10.1016/j.jtusci.2016.03.007

International Commission on Radiological Protection (ICRP). (1960). Annals of the ICRP. Annals of the ICRP, 21(1), 1-3. https://doi.org/10.1016/0146-6453(81) 90127-5

International Commission on Radiological Protection (ICRP) (1996).International Commission on Radiological Protection Age-dependent Doses to Members of the Public from Intake of Radionuclides. Part5: Compilation of Ingestion and Inhalation Coefficients ICRP Publication 72, Pergamon Press, Oxford. 
Orlunta, A. N, Sokari, S. A. \& Anele E. T. (2019, November). Assessment of Baseline Background Ionization Radiation levels within Captain Elechi Amadi Polytechnic, Rumuola, Rivers State [Paper presentation]. 42 ${ }^{\text {nd }}$ Annual Conference of the Nigerian Institute of Physics, FUT Owerri.

Qureshi, A. A., Tariq, S., Din, K. U., Manzoor, S., Calligaris, C., \& Waheed, A. (2014). Evaluation of excessive lifetime cancer risk due to natural radioactivity in the rivers sediments of Northern Pakistan. Journal of Radiation Research and Applied Sciences, 7(4), 438-447. https://doi.org/10.1016/j.jrras.2014.07.008

Rafique, M., Rahman, S. U., Basharat, M., Aziz, W., Ahmad, I., Lone, K. A., Ahmad, K., \& Matiullah. (2014). Evaluation of excess life time cancer risk from gamma dose rates in Jhelum valley. Journal of Radiation Research and Applied Sciences, 7(1), 29-35. https://doi.org/10.1016/j.jrras.2013.11.005

Sadiq, A. A., \& Agba, E. H. (2011). Indoor and Outdoor Ambient Radiation Levels in Keffi and Akwanga Towns, Nigeria. West African Journal of Science, Technology and Social Science, 1(1), 78-87.

United Nations Scientific Committee on the effect of Atomic Radiation (UNSCEAR) (2008). Report on the sources and effects of ionizing radiation, Report to the General Assembly with Scientific Annexes. United Nations, New York 